\title{
COLECTIVO IOÉ y ORTÍ, ALFONSO (2007), La convivencia en Madrid. Discursos ante el modelo de desarrollo de la ciudad y la ins- talación de población inmigrante. Observatorio de las Migraciones y de la Convivencia Intercultural de la ciudad de Madrid, Madrid.
}

Suele atribuirse a Caplow la afirmación siguiente: si no hay publicación, no hay investigación. Se transmitía así un mensaje lacónico, pero cargado de significados, muy connotado. Baste señalar aquí un aspecto de su polisemia: la idea de que una verdadera investigación ha de exponerse a la crítica de la comunidad científica. Este requisito lo cumple la obra que reseñamos, aunque de manera no convencional-tradicional ${ }^{1}$, gracias a que está disponible en el portal de Internet Colectivo Ioé-Intervención sociológica. En esta página web aparece catalogada como «inédita», junto a otra investigación de título similar también circunscrita a Madrid pero hecha mediante encuesta ${ }^{2}$. Hoy en día el conocido publish or perish (publica o perece) es ya, y lo será cada vez más en el futuro, estar o no en la red; esto es, digitalizar y archivar para su localización y consulta lo investigado. De manera que, por este flanco, el estudio firmado por el Colectivo Ioé y Alfonso Ortí se halla en el ciberespacio de nuestro nuevo mundo globalizado.

Se podría contrapesar lo señalado por el sociólogo norteamericano, con lo escrito en 1970 por el sociólogo español Carlos Moya ${ }^{3}$ : «Sociología es lo que ha- cen los sociólogos». Y, por extensión, afirmar que investigación es lo que hacen los investigadores. Ambos asertos parecen desplazar la cuestión definitoria al ser o no ser sociólogo; al ser o no ser investigador. Aunque su fuerza está en la combinación de una sencillez rotunda (y de la interpretabilidad múltiple, que deja abierta, debida a su naturaleza polisémica). Baste resaltar aquí nuestra interpretación plural de ambas sentencias, la remisión no sólo a una manera académica (o academicista incluso) de hacer sociología o de investigar, sino a los diversos modos de practicar el quehacer investigador en el oficio de la sociología ${ }^{4}$ (en tanto disciplina abierta a los demás campos del saber, al más allá de la sociología que hiciese portada de su obra maestra sobre el grupo de discusión Jesús Ibáñez).

En el caso que nos ocupa, tanto los autores concretos que figuran detrás del logo Colectivo Ioé (Walter Actis, Miguel Angel de Prada y Carlos Pereda), como Alfonso Ortí, han acumulado una experiencia investigadora muy amplia y reconocida; ya sea en el estudio de las migraciones, como en el de los métodos cualitativos, entre otros. Y es precisamente esta experticia que les precede a

${ }^{1}$ Entiéndase por lo que atañe a la edición en papel; no por el manejo bibliográfico, que incluye un entronque con los aportes de los pensadores sociales clásicos sobre las formas de sociabilidad (de convivencia). Cuestión ésta en la que se aprecia la coautoría de Ortí; así como en la atención al proceso de masificación o al concepto de sociedad masa (Giner).

${ }^{2}$ La convivencia intercultural en la ciudad de Madrid. Encuesta 2005.

${ }^{3}$ Lo que hacen los sociólogos es el título del libro homenaje a Carlos Moya Valgañón, publicado por el CIS en 2007, con más 900 páginas de colaboraciones reunidas por José Almaraz, Julio Carabaña, Emilio Lamo, Alfonso Pérez-Agote, Ramón Ramos, Miguel Requena y Marcial Romero.

${ }^{4}$ A este respecto remitimos al lector interesado al número monográfico en prensa de la Revista Política y Sociedad, titulado La trastienda de la investigación social «Sociologists at work» (Teoría e investigación concreta en primera persona), editado por Juan José Castillo, Miguel S. Valles y Catalina Wainerman. 
los primeros, acompañada de la maestría de Ortí, lo que vuelve a plasmarse en esta investigación. Hasta el punto que cabría hablar de un estilo de investigación IoéOrtí, que ya quedó explicitado (en parte) en el estudio pionero de $1995^{5}$ elaborado por Ioé. En dicho estudio se reconocía explícitamente la deuda intelectual contraída con Ortí. Concretamente, la arquitectura teórico-conceptual de posiciones ideológicas típicas expresada gráficamente en las conclusiones del informe ${ }^{6}$.

En el estudio de 2007 que reseñamos aquí (en nota a pie de la página 137), se hace referencia al trabajo primero de 1995, de esta guisa: «Los ejes básicos del esquema de posiciones respecto a la población inmigrante no difieren sustancialmente de los detectados en otro estudio cualitativo realizado en $1995 »^{7}$. Lo cual nos da pie para plantear algunas reflexiones metodológicas. Por un lado, parece lograrse un análisis trascendente, que va más allá del momento histórico concreto en el que se levantan las discusiones gru- pales particulares. Se cumpliría así el sueño de muchos analistas, desvelar las claves, las lógicas, vislumbrar los escenarios futuros posibles. Sin duda, se trata de una aproximación eminentemente sociológica, más orientada a la generalización que a la concreción; en la que no falta la advertencia al lector del carácter «arquetípico» de los modelos de sociedad interiorizados por los grupos de autóctonos, y de los «modos de instalación de los grupos inmigrantes». Pero, por otro lado, pareciera correrse el riesgo de alejarse en exceso del referente empírico de partida. Algo que los autores resuelven, con gran pericia, flexibilizando el esquema de posiciones discursivas básicas ante la inmigración (a: rechazo xenófobo, b: integración formal, c: inserción subalterna, d: aceptación instituyente), que se convierte en el esquema maestro de la parte segunda (y principal) del informe. Y lo consiguen recurriendo a (casi) todo el abecedario latino (salvo la $11, \tilde{\mathrm{n}}, \mathrm{y}, \mathrm{z})^{8}$. Recursos retóricos aparte (pero que sin duda

${ }^{5}$ Me refiero a Discursos de los españoles sobre los extranjeros. Paradojas de la alteridad. Estudio 2119 del CIS, publicado en 1995, en la colección Opiniones y actitudes (n. $\left.{ }^{\circ} 8\right)$. El encargo se produjo siendo Presidente del CIS Joaquín Arango, especialista destacado en Sociología de las migraciones internacionales. Los autores comenzaban así su informe: «Durante los últimos años ha surgido en España un nuevo «tema de moda»: la inmigración extranjera y las cuestiones relacionadas con el racismo y la xenofobia» (p. 7). La presencia inmigratoria no había experimentado aún el crecimiento rampante posterior, que hoy conocemos.

${ }^{6}$ Se cita por parte de Ioé la ponencia de Alfonso Ortí ( «Génesis y estructura de la sociedad de masas. La formación de los medios de comunicación masiva»), pronunciada en julio de 1994, durante el curso de verano en El Escorial dirigido por Angel de Lucas sobre Las prácticas cualitativas de investigación social. Pero la concepción (intuición documentada) de Ortí de su esquema del proceso de modernización en la España de los 60, como génesis de su modelo tipológico (o cuadrado $M)$, hay que remontarla a su contribución en la obra colectiva editada por Martínez Cuadrado (1969) Cambio social y modernización política. Madrid: Cuadernos para el Diálogo.

${ }^{7}$ Se refieren al cuadro de «posiciones típico-ideales respecto a «lo extranjero»» que aparece en la página 107. Allí se plantea un interrogante que cabe repetir hoy para el estudio de 2007: «¿En qué medida pueden adscribirse los discursos concretos, detectados por el análisis empírico, a este modelo de referencia?». Téngase en cuenta que el estudio de 1995 tenía una proyección nacional, española; mientras que el de 2007 se circunscribe a la ciudad de Madrid.

${ }^{8}$ El lector se percatará mejor del alcance de esta observación al comparar los cuadros 16 y 17 del texto que comentamos. $\mathrm{O}$, antes incluso, en la introducción a la primera parte (pp. 15-ss), en el cuadro 4 y siguientes, donde las 24 fracciones discursivas se ubican gráficamente en relación a las tres clases sociales de referencia; a los tres discursos ideológicos de referencia (desglosados en seis); con especificación de en qué grupos de discusión, de los 12 realizados han surgido.

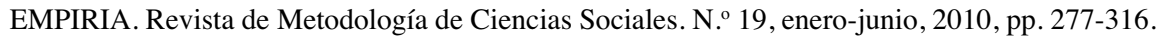
ISSN: $1139-5737$ 
dejan su huella, la de un regusto por la estética y la lógica del orden racional, a nuestra humilde interpretación, además de resultar muy prácticos), se ofrece una necesaria concreción analítica a través de la noción de fracciones discursivas. Y se hace de manera que dichas fracciones discursivas quedan etiquetadas con un perfil sociológico muy útil; e identificadas con su correspondiente clase social de pertenencia (en la terminología de Ortí: clases medias funcionales, pequeña burguesía patrimonial, clases populares trabajadoras). Se llega a componer un esquema muy visual de los discursos ante la inmigración (que ya no arranca solo de los autóctonos, ni tampoco se proyecta únicamente sobre lo extranjero $\left.{ }^{9}\right)$, que se materializa en el cuadro 17 (p. 142), en el que se agrupan por bloques las fracciones afines, abundando en las posibilidades de flexibilización de estas nuevas agrupaciones, pero sin perder de vista su «ubicación topológica» en el esquema de cuatro discursos básicos, que ahora aparecen representados de manera más elástica y dinámica, también más intersticial.

Hecha esta primera presentación, de la obra y sus autores, añadiré algunas anotaciones complementarias que me ha suscitado su lectura, hasta agotar el número de palabras asignado a esta reseña.
Se abre y se cierra el texto (en tanto compendio narrativo elegido para presentar la labor analítica e interpretativa desplegada) resaltando la perspectiva de clase ${ }^{10}$, sin duda la más sociológica. Y se hace bien en la versión triple (con la que se organizan los tres capítulos de la primera parte); bien en la versión doble (expresada en los epígrafes de la tercera parte: Madrid en clave burguesa, Madrid en clave popular).

Se lea ordenada o desordenadamente, en las tres partes del informe redactado encontramos la noción clave e innovadora de las fracciones discursivas (a las que ya me he referido, pero conviene añadir algo más). Desde el principio, en la presentación de los grupos de discusión se ofrece un desglose de fracciones que supone en ocasiones (como el GD1, entre otros) advertir la presencia de varias de éstas en un mismo grupo. Algo que pudiera resultar llamativo al contrastarlo con la vieja idea, trasmitida por algunos maestros, acerca de la existencia de un discurso por grupo. De nuevo, cabe decir que se resuelve esta potencial controversia flexibilizando el criterio metodológico ${ }^{11}$. Y así se afirma, por ejemplo, que: «El Cuadro 9 presenta un esquema de las cuatro fracciones discursivas correspondientes a la posición xenófoba

${ }^{9}$ Este seguramente sea otro de los aciertos del estudio de 2007, respecto al de 1995. De los doce grupos de discusión proyectados y realizados, la mitad se hacen con autóctonos solo, tres con inmigrantes solo, y tres mixtos. Por otro lado, el abordaje de la inmigración y de lo extranjero se hace ahora fijando como norte macro-temático y de intervención social (sociológica y política) la cuestión de fondo de la convivencia.

${ }^{10}$ Quizá menos declarada o explicitada, pero la investigación cuenta también con una perspectiva histórica. Por un lado, imbricada en el aparato teórico-analítico desarrollado por Alfonso Ortí acerca del concepto de modernización y cambio social, al que ya nos hemos referido. Por otro, debido a la orientación temática específica alrededor de los discursos en torno a la evolución de Madrid, y en general de los españoles y su experiencia migratoria pasada (emigración interior, internacional) o presente (inmigración). Algo que se plasma en el diseño específico de los grupos de discusión con autóctonos, al asegurar en la contactación una portavocía de esa emigración española interior con destino Madrid. Por último, quizá no esté de más recordar la primacía dada por Ortí a la «perspectiva histórico-social crítica», en su visión del proceso investigador.

11 Y señalando que las posiciones básicas comunes a varias fracciones discursivas se producen mediante la «articulación de fracciones de clase». 
(...) Se trata de una elaboración tipológica, que contrapone lógicas discursivas diferenciadas, aunque en la práctica social se encuentren frecuentemente fundidas o solapadas entre sí y con otras posiciones» (p. 66).

Diríase que la necesidad analítica, como constante a lo largo del informe, de detallar fracciones discursivas apunta a otra necesidad metodológica. Me refiero a la combinación de los discursos grupales (más o menos compactos o compactados analíticamente) con las trayectorias o experiencias biográficas (individuales y sociales a un tiempo ${ }^{12}$ ). Se echa en falta el complemento de las entrevistas, las historias de vida, los ma- teriales documentales (de diverso tipo, que la sociedad produce), o los de observación-participación etnográfica; estos últimos especialmente útiles para contrastar el discurso (lo que se dice) con los comportamientos (lo que se hace). A este respecto, el estudio se repliega o ensimisma en el método cualitativo de los grupos de discusión. Una consideración con ribetes críticos, por nuestra parte, que advierte de la opción decidida por los autores del estudio reseñado (entre otras posibles); al tiempo que ha de entenderse también como preferencia o escoramiento del autor de la reseña ${ }^{13}$.

Miguel S. Vallés

${ }^{12}$ En sintonía con lo expresado por González García acerca del vocablo representaciones individuales/colectivas, en tanto dualismo a superar (Diccionario de Sociología editado por Giner, Lamo y Torres, segunda edición, 2006).

${ }_{13}$ Véase a este respecto nuestra particular visión del campo de los métodos de investigación sociológica en España: Valles Martínez, M. S.(2007) «Metodología y técnicas de investigación», en Pérez-Yruela, M. y (compiladores), Sociología en España. Madrid. CIS y FES: 49-71. O la apuesta por el enfoque biográfico en el estudio de las migraciones intra e internacionales: (2009) «Metodología biográfica y experiencia migratoria: actualidad del enfoque de los testimonios anónimos y de autor en el legado de Juan F. Marsal», Papers, 91: 103-125.

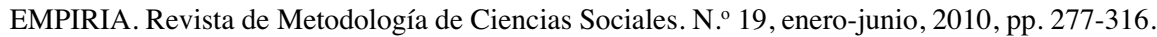
ISSN: 1139-5737 